\title{
THE
}

\section{Ocean Data Assimilation and Initialization Procedure for the Coupled GFDL/URI Hurricane Prediction System}

Aleksandr Falkovich

Isaac Ginis

University of Rhode Island, iginis@uri.edu

Stephen Lord

Follow this and additional works at: https://digitalcommons.uri.edu/gsofacpubs

\section{Citation/Publisher Attribution}

Falkovich, A., Ginis, I., \& Lord, S. (2005). Ocean Data Assimilation and Initialization Procedure for the Coupled GFDL/URI Hurricane Prediction System. Journal of Atmospheric and Oceanic Technology, 22, 1918-1932. doi: 10.1175/JTECH1810.1

Available at: https://doi.org/10.1175/JTECH1810.1

This Article is brought to you for free and open access by the Graduate School of Oceanography at DigitalCommons@URI. It has been accepted for inclusion in Graduate School of Oceanography Faculty Publications by an authorized administrator of DigitalCommons@URI. For more information, please contact digitalcommons-group@uri.edu. 


\title{
Ocean Data Assimilation and Initialization Procedure for the Coupled GFDL/URI Hurricane Prediction System
}

\author{
Aleksandr Falkovich \\ NOAA/NCEP/EMC, Camp Springs, Maryland \\ ISAAC GINIS \\ Graduate School of Oceanography, University of Rhode Island, Narragansett, Rhode Island \\ STEPHEN LORD \\ NOAA/NCEP/EMC, Camp Springs, Maryland
}

(Manuscript received 9 April 2004, in final form 5 May 2005)

\begin{abstract}
A new ocean data assimilation and initialization procedure is presented. It was developed to obtain more realistic initial ocean conditions, including the position and structure of the Gulf Stream (GS) and Loop Current (LC), in the Geophysical Fluid Dynamics Laboratory/University of Rhode Island (GFDL/URI) coupled hurricane prediction system used operationally at the National Centers for Environmental Prediction. This procedure is based on a feature-modeling approach that allows a realistic simulation of the cross-frontal temperature, salinity, and velocity of oceanic fronts. While previous feature models used analytical formulas to represent frontal structures, the new procedure uses the innovative method of cross-frontal "sharpening" of the background temperature and salinity fields. The sharpening is guided by observed cross sections obtained in specialized field experiments in the GS. The ocean currents are spun up by integrating the ocean model for 2 days, which was sufficient for the velocity fields to adjust to the strong gradients of temperature and salinity in the main thermocline in the GS and LC. A new feature-modeling approach was also developed for the initialization of a multicurrent system in the Caribbean Sea, which provides the LC source. The initialization procedure is demonstrated for coupled model forecasts of Hurricane Isidore (2002).
\end{abstract}

\section{Introduction}

Recent studies show that the intensity of tropical cyclones is largely controlled by the thermodynamic properties of the atmosphere and upper ocean along the storm track (Emanuel 1999; Bender and Ginis 2000; Bao et al. 2000). In 2001, the Geophysical Fluid Dynamics Laboratory/University of Rhode Island (GFDL/ URI) coupled hurricane-ocean model was implemented operationally at the National Centers for Environmental Prediction (NCEP) for all tropical storms in the Gulf of Mexico and Atlantic basins. The experi-

Corresponding author address: Isaac Ginis, Graduate School of Oceanography, University of Rhode Island, Narragansett, RI 02882 .

E-mail: iginis@gso.uri.edu ence with the GFDL/URI coupled model emphasized the importance of proper initialization of the coupled modeling system. It is well known that successful forecasts of the structure and movement of tropical cyclones using an atmospheric model alone are strongly dependent on good initialization. In a coupled model, the ocean initialization is equally important, because SST response is very sensitive to the upper ocean structure. Therefore, an accurate prediction of tropical cyclones requires proper initialization of both the atmospheric and oceanic components of the modeling system, as well as accurate measurements of the ocean ahead of the storm and skillful assimilation of the ocean data into the ocean model.

The purpose of this paper is to describe the new ocean data assimilation and initialization procedure developed for the GFDL/URI coupled hurricane prediction system. The new procedure is designed to obtain 
more realistic initial ocean fields, including the position and 3D structure of the major fronts in the Atlantic basin: the Gulf Stream (GS) and Loop Current (LC). These fronts are important for hurricane forecasting, as they may influence the SST response in the coupled model and thus the track and intensity of hurricanes. The ocean data assimilation and initialization procedure in the 2001 operational GFDL/URI coupled model is described in Bender and Ginis (2000). Some additional modifications were made in 2002 and will be referred to hereafter as OP02. The initial currents in OP02, including GS and LC, were generated by a model spinup using the General Digital Environmental Model (GDEM) monthly temperature and salinity climatology and specified inflow/outflow boundary conditions. The Atlantic basin was divided into three regions: the Gulf of Mexico, western Atlantic, and eastern Atlantic. This resulted in an occasional loss of ocean coupling when a hurricane moved from one region to another during a forecast. In the new 2003 version (OPO3) that will be described in this paper, the Gulf of Mexico and western Atlantic regions are combined into a single computational domain to rectify this problem.

The new data assimilation and initialization procedure is based on a feature-modeling approach. This approach was originally introduced by Robinson et al. (1989) and Lozano et al. (1996) and was successfully used for modeling and forecasting the Gulf Stream and other oceanic fronts by Gangopadhyay et al. (1997), Robinson and Gangopadhyay (1997), and Gangopadhyay and Robinson (1997). Using ocean climatology data and the results of field experiments, they proposed analytical formulas with a set of parameters for the velocity profiles that characterize the Gulf Stream, the Deep Western Boundary Current, the southern and northern recirculation gyres, and the slope water gyre and rings. To recover temperature and salinity fields, they used a water mass model specifically developed for this part of the western North Atlantic region by Spall and Robinson (1990) and later modified by Lozano et al. (1996). The water mass model is based upon a temperature interpolation function between the Slope Water and the Sargasso Sea, and a bimodal temperaturesalinity relationship. Their feature model successfully simulated and predicted the evolution of the GS and ring detachment during the Data Assimilation and Model Evaluation Experiment (Lai et al. 1994).

The size of the united domain in the GFDL/URI coupled model is many times larger than the part of the western North Atlantic region used in the above studies. Therefore, it is difficult to convert the velocity field to temperature and salinity fields using a simple water mass model. Here, we introduce a new approach to feature modeling in which we begin by constructing temperature and salinity fields that characterize the typical structure of the GS and LC by using a crossfront "sharpening" procedure. The associated currents are calculated by a short (typically 2 day) integration of a primitive equation ocean model, which is sufficient to generate dynamically adjusted fields.

The rest of this paper has the following structure. The 2002 operational GFDL/URI ocean initialization and data assimilation system is briefly discussed in section 2 . A description of the new 2003 ocean data assimilation procedure (OP03) is given in section 3. Section 4 describes a methodology for future improvements of the GFDL/URI model, which includes initialization of the multicurrent system (MCS) in the Caribbean Sea. The conclusions can be found in section 5 .

\section{The 2002 ocean initialization and data assimilation procedure in the GFDL/URI model}

A version of the Princeton Ocean Model (POM) (Blumberg and Mellor 1987) is used in the GFDL/URI coupled system, with a horizontal resolution of $1 / 6^{\circ}$ and 23 vertical sigma levels (Bender and Ginis 2000). The ocean initialization and data assimilation procedures used operationally at NCEP in 2002 (OP02) included four phases. They were designed to spin up the velocity and sea surface elevation fields from the Navy's General Digital Environmental Model (GDEM) monthly temperature and salinity data (Teague et al. 1990), to assimilate the daily global NCEP SST data and to create the hurricane-induced cold wake. During phase 1, the POM was integrated in a diagnostic mode (e.g., holding the temperature and salinity constant) for 0.5 months from the GDEM monthly temperature and salinity fields, which were interpolated from the original $0.5^{\circ}$ resolution and 33 vertical $Z$ levels onto the POM grid points. phase 1 was followed by a 2 -month integration in a prognostic mode, keeping the SST fixed in time (phase 2). The first two phases thus generated dynamically consistent current, temperature, and salinity fields for each month of the June to November hurricane season. The last two phases are designed to adjust the SST and upper ocean structure at the beginning of each hurricane forecast. In phase 3, the daily NCEP SST is assimilated within the mixed layer. The POM is then integrated for 2 days for dynamic adjustment, keeping the SST fixed in time. In phase 4, the cold wake at the sea surface and the currents produced by the storm prior to the beginning of coupled model forecast are generated. The ocean model is integrated for 3 days 

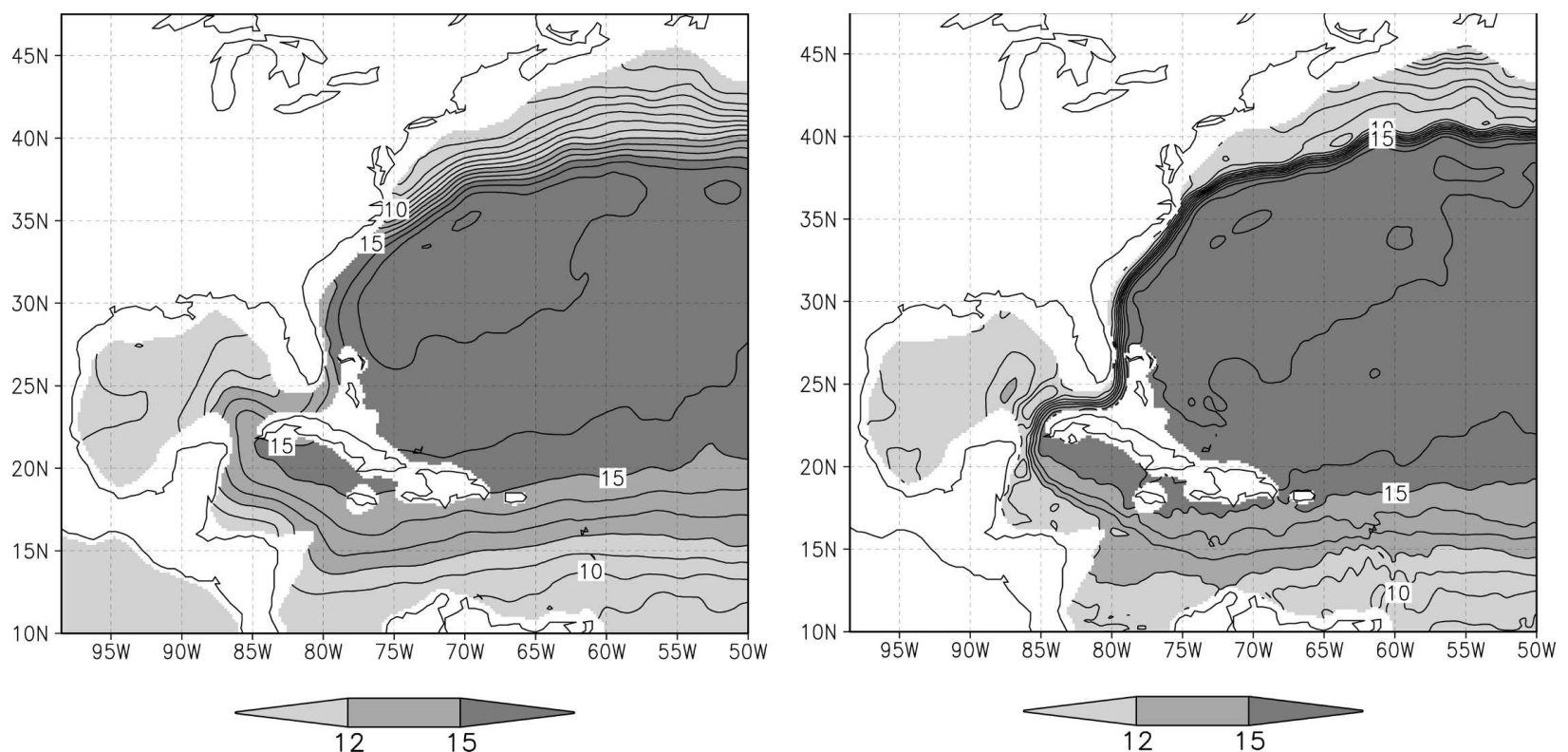

FIG. 1. Temperature at $400 \mathrm{~m}$ : (left) in the GDEM Sep climatology and (right) after phase 1 of the OP03 model initialization during Hurricane Isidore forecast.

and forced using the observed hurricane surface wind distribution provided by the National Hurricane Center along the storm track [see Bender and Ginis (2000) for details].

In OP02, the Atlantic basin was divided into three regions: Gulf of Mexico $\left(15^{\circ}-31^{\circ} \mathrm{N}, 98.5^{\circ}-75^{\circ} \mathrm{W}\right)$, west Atlantic $\left(10^{\circ}-47.5^{\circ} \mathrm{N}, 82^{\circ}-50^{\circ} \mathrm{W}\right)$, and east Atlantic $\left(10^{\circ}-40^{\circ} \mathrm{N}, 60^{\circ}-30^{\circ} \mathrm{W}\right)$. In the west Atlantic region, an inflow was prescribed at the western boundary $\left(82^{\circ} \mathrm{W}\right)$ between Cuba and Florida and an outflow at the eastern boundary $\left(50^{\circ} \mathrm{W}\right)$ near $40^{\circ} \mathrm{N}$. During the 2.5 -month model integration in phases 1 and 2, a GS-type current was spun up in the west Atlantic region due to the inflow/outflow lateral boundary conditions and the temperature gradients in the main thermocline. Similarly, an LC-type current was spun up in the Gulf of Mexico region due to a specified inflow near the eastsouth corner of the domain and the outflow at the northern boundary around the GS.

The main shortcoming of this approach is that the currents corresponding to the GS and LC after model spinup are not very realistic. During a spinup of integration, the trajectories of the LC and GS deviate significantly from the initial positions and become very wide and sometime not continuous. More importantly, it is not possible to control the GS and LC paths in the model in order to make them consistent with the real paths at the time of the hurricane forecast. A new initialization and data assimilation procedure described below was developed to overcome these limitations.

\section{New initialization and data assimilation procedure}

The new initialization and data assimilation procedure is based on a feature-modeling approach that we use for the GS and LC initialization in the GFDL/URI model. The essence of this approach is to simulate the GS and LC paths and their cross-frontal structures as realistically as possible at the beginning of the hurricane model forecast. The main assumption in this approach is that the cross-frontal temperature, salinity, and velocity structures in the upper and main thermocline do not change significantly along a strong oceanic front such as the GS. This assumption is well supported by data obtained in specialized field experiments (Halkin and Rossby 1985; Leaman et al. 1989; Hogg 1992; Johns et al. 1995; Bower and Hogg 1996; Rossby and Gottlieb 1998; Rossby and Zhang 2001). Feature models can be either velocity based or temperature-salinity based. In the previous studies, simple analytical data-based formulas are used to represent the "featured" frontal structure (Gangopadhyay and Robinson 2002). We utilize a new approach here, which is based on cross-frontal "sharpening" of the climatological temperature and salinity fields where the fronts are usually poorly represented due to a coarse spatial resolution.

The first step in the initialization procedure is to specify continuous paths for the GS and LC within the united ocean domain (Fig. 1), which includes the west- 
ern Atlantic and the Gulf of Mexico $\left(10^{\circ}-47.5^{\circ} \mathrm{N}, 98.5^{\circ}-\right.$ $50^{\circ} \mathrm{W}$ ). West of Cape Hatteras (from $82^{\circ}$ to $75^{\circ} \mathrm{W}$ ), where the GS is typically very stable, its path is specified using long-term averaged data, as in Leaman et al. (1989). East of Cape Hatteras (from $75^{\circ}$ to $50^{\circ} \mathrm{W}$ ) we use satellite-derived monthly North Wall data provided by P. Cornillon (2003, personal communication). Note that the GS center in the main thermocline is usually shifted by about $14 \mathrm{~km}$ to the south from the North Wall (Cornillon and Watts 1987). In the Gulf of Mexico, we determine the LC path using the maximum temperature gradients in the main thermocline in the GDEM climatology data. For the LC source, we initialize a weak current along the $12^{\circ} \mathrm{C}$ isotherm at $z=400$ $\mathrm{m}$ in the GDEM data (from $50^{\circ}$ to $70^{\circ} \mathrm{W}$ ) in the southern part of the region $\left(15^{\circ}-16^{\circ} \mathrm{N}\right)$ and connect it with the LC near the Yucatan Strait. This current, while not very realistic, is needed to support the LC in the model. In the next section, we discuss a multicurrent initialization procedure in the Caribbean Sea that allows a more realistic specification of the LC source.

After the GS and LC paths are defined, normal cross sections with a $5^{\circ}$ width $\left(2.5^{\circ}\right.$ from each side $)$ are constructed with $0.1^{\circ}$ increments along the paths. The background GDEM temperature and salinity fields are then interpolated at each $z$ level onto these cross sections (also with $0.1^{\circ}$ increments) using a bilinear interpolation. In each cross section, the center of the GS, which is determined by the intersection of the $12^{\circ} \mathrm{C}$ isotherm and $z=400 \mathrm{~m}$ in the GDEM climatology, is displaced to the location of the new path. In the next step, the temperature gradients are sharpened in each cross section according to observational data obtained in field experiments (Halkin and Rossby 1985; Leaman et al. 1989; Hogg 1992; Johns et al. 1995; Bower and Hogg 1996). Sharpening is done by changing the temperatures at each $z$ level along the cross section in such a way that the new temperature gradients are consistent with the observations. The salinity gradients are also sharpened around the new GS center in a similar way. The gradients are modified within an area of $1.6^{\circ}\left(0.8^{\circ}\right.$ from each side of the path); the remaining area is used for blending the modified temperatures and salinities with the background fields. A similar procedure but only for temperature is applied to create the LC in the Gulf of Mexico. In sharpening the LC area we use the same gradients of temperature as in the GS but multiplied by a coefficient that increases along the LC path from 0.2 at $50^{\circ} \mathrm{W}$ (the $\mathrm{LC}$ source) to 1.0 at $82^{\circ} \mathrm{W}$ (where the LC turns into the GS). Note that in order to simulate a weaker current in the region where the LC originates, the cross-front gradient there is chosen to be 5 times less than the gradient used in the GS.
After sharpening, the temperature and salinity fields are interpolated back from the cross sections onto the model grid system. The initial baroclinic velocities are calculated from geostrophic balance equations assuming zero elevation. Starting with these fields and assuming zero barotropic velocities, the ocean currents are spun up by integrating the POM equations. The inflow/ outflow lateral boundary conditions are set only at the eastern boundary of the united region, where we specify the following transports: an outflow of $90 \mathrm{~Sv}(1$ $\mathrm{Sv} \equiv 10^{6} \mathrm{~m}^{3} \mathrm{~s}^{-1}$ ) between $39^{\circ}$ and $40.5^{\circ} \mathrm{N}$ (GS), an inflow of $30 \mathrm{~Sv}$ between $41^{\circ}$ and $43^{\circ} \mathrm{N}$ (north of GS), and an inflow of $60 \mathrm{~Sv}$ between $14^{\circ}$ and $18^{\circ} \mathrm{N}$ (south of GS). We should note that the lateral boundary conditions do not play an important role in this procedure because the currents associated with the GS and LC are primarily formed by very rapid dynamical adjustment of the velocity and mass fields. We find that a 2-day model integration is sufficient to dynamically adjust the velocity fields to the strong gradients of temperature and salinity in the main thermocline in the GS and LC.

The new ocean initialization and data assimilation procedure was extensively tested for hurricanes during previous hurricane seasons and was implemented into the 2003 operational version of the GFDL/URI coupled hurricane-ocean model (OP03). The fourphase ocean model initialization in OP02 was reduced to two phases; the spinups of currents in the old phases 1 and 2 were eliminated. In OP03, the new initialization procedure is performed in phase 1 , together with the assimilation of NCEP SST as in the old phase 3. In this phase, the daily NCEP SST is assimilated within the mixed layer. The POM is then integrated for 2 days for dynamic adjustment, keeping the SST fixed in time. The OP03 phase 2 is the same as the old phase 4 . In this phase, the cold wake at the sea surface and the currents produced by the hurricane prior to the beginning of coupled model forecast are generated. The ocean model is integrated for 3 days and forced using the observed hurricane surface wind distribution provided by the National Hurricane Center along the storm track.

We consider, as an example, the GFDL/URI model forecast of Hurricane Isidore initiated at 1200 UTC 19 September 2002. During this forecast the hurricane moved slowly from the Caribbean Sea into the Gulf of Mexico and crossed the LC. Figure 1 shows the 400-m temperatures in the GDEM climatology for the month of September (left) and after the sharpening procedure and phase 1 (right). The temperature gradients in the GDEM data are very smooth, and the GS and LC fronts are poorly identified. After sharpening, both fronts appear to be well defined and more realistic. 


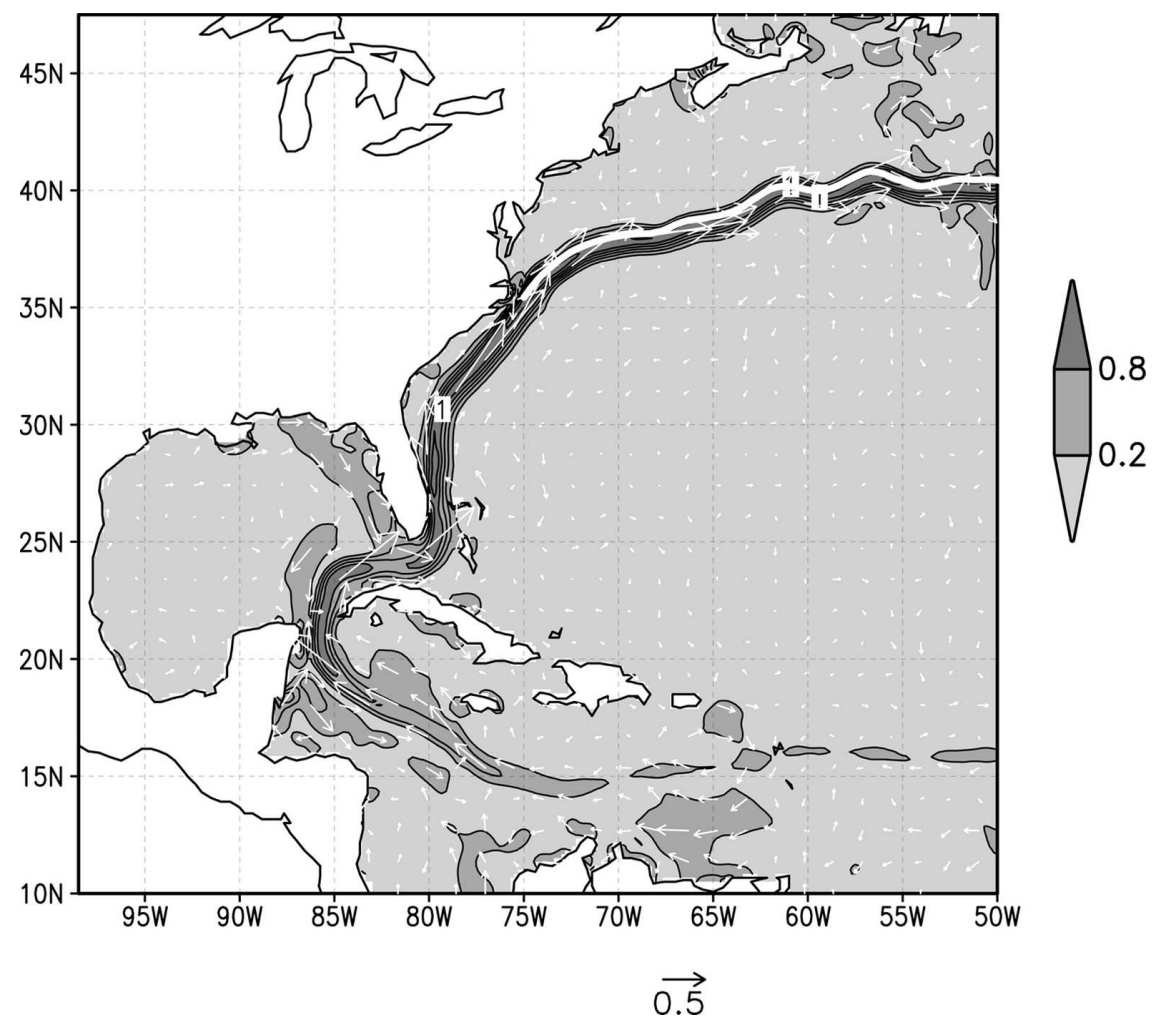

FIG. 2. Surface current after phase 1 of the OP03 model initialization during Hurricane Isidore forecast. White line indicates the GS North Wall in Sep.

Figure 2 shows the surface currents after a 2-day model spinup in phase 1 . Strong currents have developed along the LC and GS fronts, with the maximum velocity reaching $1.7 \mathrm{~m} \mathrm{~s}^{-1}$. When comparing Figs. 1 and 2, it is evident that the LC follows the sharpened GDEM temperature gradients in the main thermocline in the Gulf of Mexico, and the GS follows very well the specified North Wall. Figure 3 shows the meridional cross sections through the GS along $68^{\circ} \mathrm{W}$ in the GDEM climatology (left) and after the sharpening procedure and phase 1 (right). They again illustrate how weak temperature gradients across the GS in the GDEM climatology are transformed into a sharp, more realistic front. Figure 4 shows zonal (downstream) GS velocity in a cross section along $68^{\circ} \mathrm{W}$ after phase 1 (left) and after a 3-day coupled model forecast (right). A strong jet with a GS-like structure is developed in the upper layer. Comparing the right- and left-hand panels of Fig. 4 , it is evident that the cross-stream velocity structure in the jet is maintained very well during the 6 days of model integration ( 3 days of phase 2 and 3 days of the coupled model forecast).

It is interesting to compare the temperature and velocity cross sections in the model with observations obtained during field experiments in the GS. Figure 5, adopted from Leaman et al. (1989), shows mean temperature (left) and downstream velocity (right) through the GS (near $73^{\circ} \mathrm{W}$ ) obtained during the Pegasus experiment. Johns et al. (1995) compared the downstream velocity obtained near $73^{\circ} \mathrm{W}$ with the velocity obtained in the Synoptic Ocean Prediction (SYNOP) experiment at $68^{\circ} \mathrm{W}$, and found that the two resembled each other very closely. The temperature cross section after initialization (Fig. 3, right) is in good agreement with the observed cross section in Fig. 5. A comparison of Figs. 4 and 5 shows that the overall velocity structure in the model is consistent with the real GS. However, the horizontal resolution in the model is not sufficient to reproduce the maximum velocity found in the observational data.

\section{Initialization of a multicurrent system in the Caribbean Sea}

One of the important advantages of the feature modeling approach is that it allows the initialization of a multicurrent system (MCS) in an ocean model. We utilize this approach to initialize the MCS in the Caribbean Sea and adjacent regions in the GFDL/URI hurricane model. To construct initial ocean currents that 

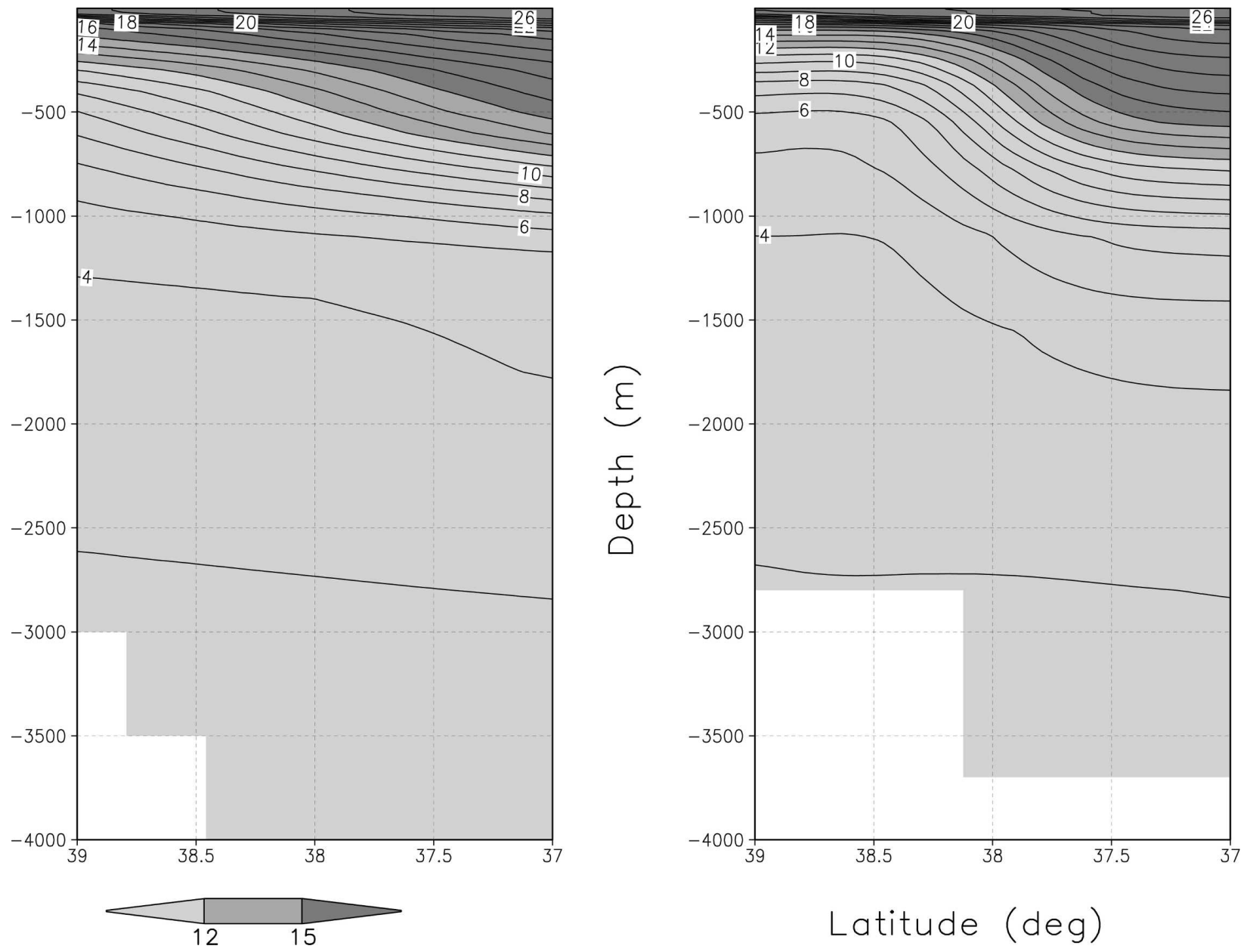

FIG. 3. Temperature cross section through the GS along $68^{\circ} \mathrm{W}$ : (left) in the GDEM Sep climatology and (right) after phase 1 of the OP03 model initialization during Hurricane Isidore forecast.

represent the continuous and strong LC and GS, we need to specify a source of the LC in the Caribbean. In OP03 we specified a source of the LC as a weak single current originated at the eastern boundary of the domain near $16^{\circ} \mathrm{N}$ and with increased speed as it approached the LC. Such description of the ocean circulation in the Caribbean Sea is not very realistic. Therefore, we utilized in this study the results of Johns et al. (1999), who processed ship observations in different passages between islands in the Atlantic Ocean and the Intra-Americas Sea and proposed more complex representation of the source of the LC. Figure 6 shows the MCS in this region according to Johns et al. (1999). We should note that such narrow coherent currents hardly exist in the long-term averaged circulation in the Caribbean Sea. We utilize the MCS from Johns et al. (1999) only as an illustration of our methodology, which allows construction of a more realistic multicurrent system with predefined paths as a source of the LC.
To continue the currents in the MCS to the east of the Caribbean Sea, we use the temperature cross sections along $54^{\circ}$ and $65^{\circ} \mathrm{W}$ from the World Ocean Circulation Experiment (WOCE) electronic atlas (eWOCE; available online at http://www.ewoce.org). In these cross sections we can identify fronts as the regions with sharp temperature gradients in the thermocline. We assume that the extensions of the MCS paths to the eastern part of the computational domain are associated with these fronts and elongated in a zonal direction. This is, of course, a much idealized representation of the ocean circulation in the region, but it is a reasonable first approximation. This idealization is justified in the present study since it is utilized for illustration purposes only.

In the MCS initialization, we replaced the GDEM climatology used in $\mathrm{OP} 03$ by a higher $\left(0.25^{\circ}\right)$ resolution Levitus annual temperature and salinity climatology (Boyer and Levitus 1997). Due to better horizontal 

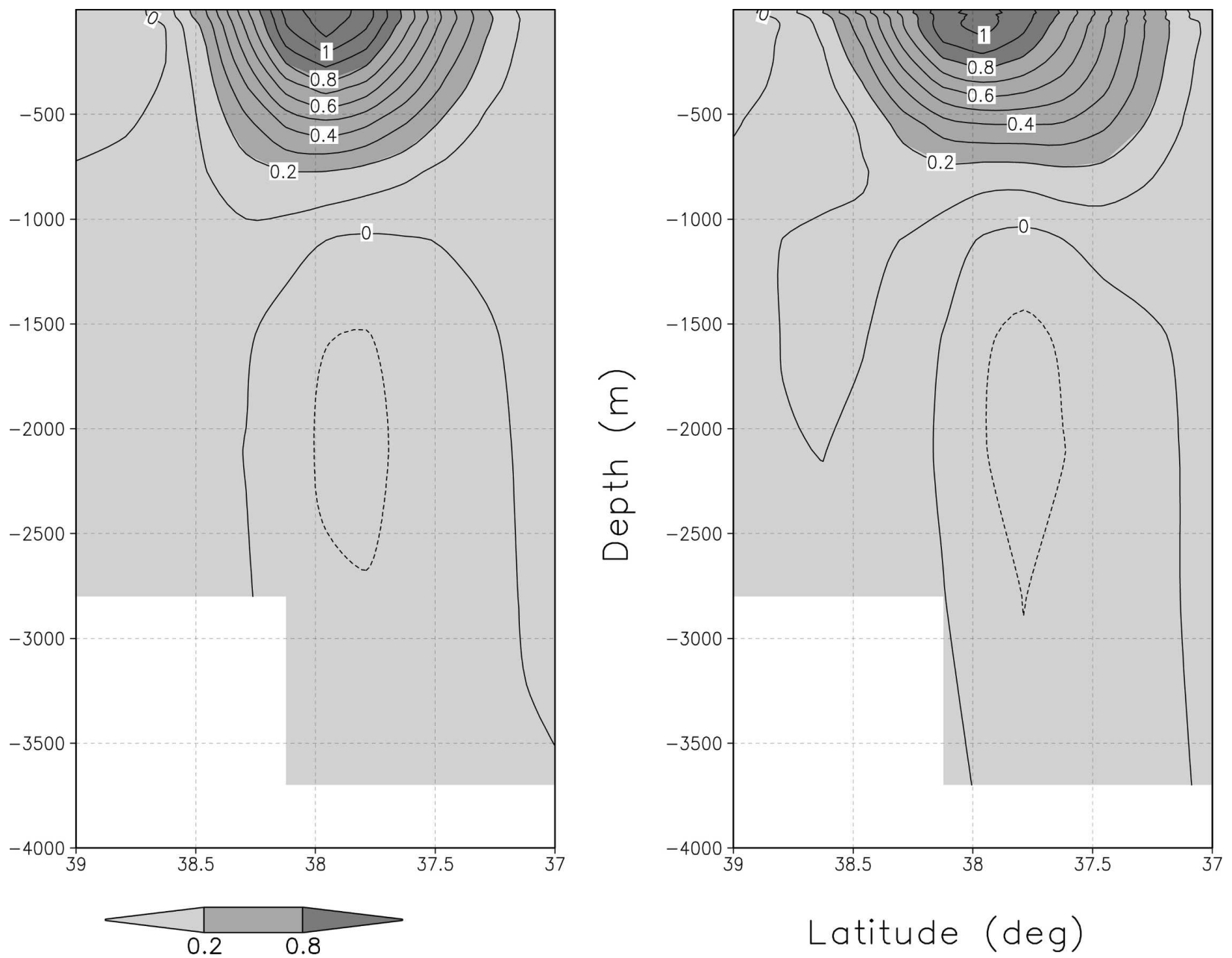

FIG. 4. Downstream velocity cross section through the GS near $68^{\circ} \mathrm{W}$ : (left) after phase 1 and (right) after 3 days of the coupled Hurricane Isidore forecast with the OP03 model initialization.

resolution of the Levitus climatology, the LC structure in the Gulf of Mexico is better represented, and therefore preferred. But the annually averaged Levitus climatology cannot be used in the mixed layer during the hurricane season. Therefore, we have created hybrid data, where we inserted the GDEM monthly mixed layer temperatures into the Levitus annual climatology. After insertion, the temperatures below the mixed layer are adjusted using the same procedure as in phase 1.

After the current paths corresponding to the MCS are specified, cross sections normal to the paths are constructed (as in OP03). We then identify lines that separate neighboring currents at equal distances from the current centers. If the distance between the separation line and the current center exceeds $2.5^{\circ}$, the line is constructed at a distance of $2.5^{\circ}$ from the path. For each $z$ level in a cross section perpendicular to the path, we find the maximum from the right (minimum from the left) temperature between the current center and the separation line and sharpen the gradient using the difference between this maximum (minimum) value and the temperature at the current center. The sharpening at each level is guided by the gradients derived from observed GS cross sections, such that the crossfrontal gradients become consistent with those observed in the GS. Figure 7 (left) shows the hybrid GDEM September and Levitus temperature field in the cross section along $54^{\circ} \mathrm{W}$ from $10^{\circ}$ to $24^{\circ} \mathrm{N}$. At this longitude, the current paths in the multicurrent system are nearly zonal. Figure 7 (right) shows the same cross section, but after applying the sharpening procedure and 2-day model spinup in phase 1.

A comparison of the left- and right-hand panels of Fig. 7 illustrates how the smooth climatological temperature gradients in the main thermocline are replaced by temperature fronts with sharp gradients separated by nearly constant temperatures. The LC path in the 

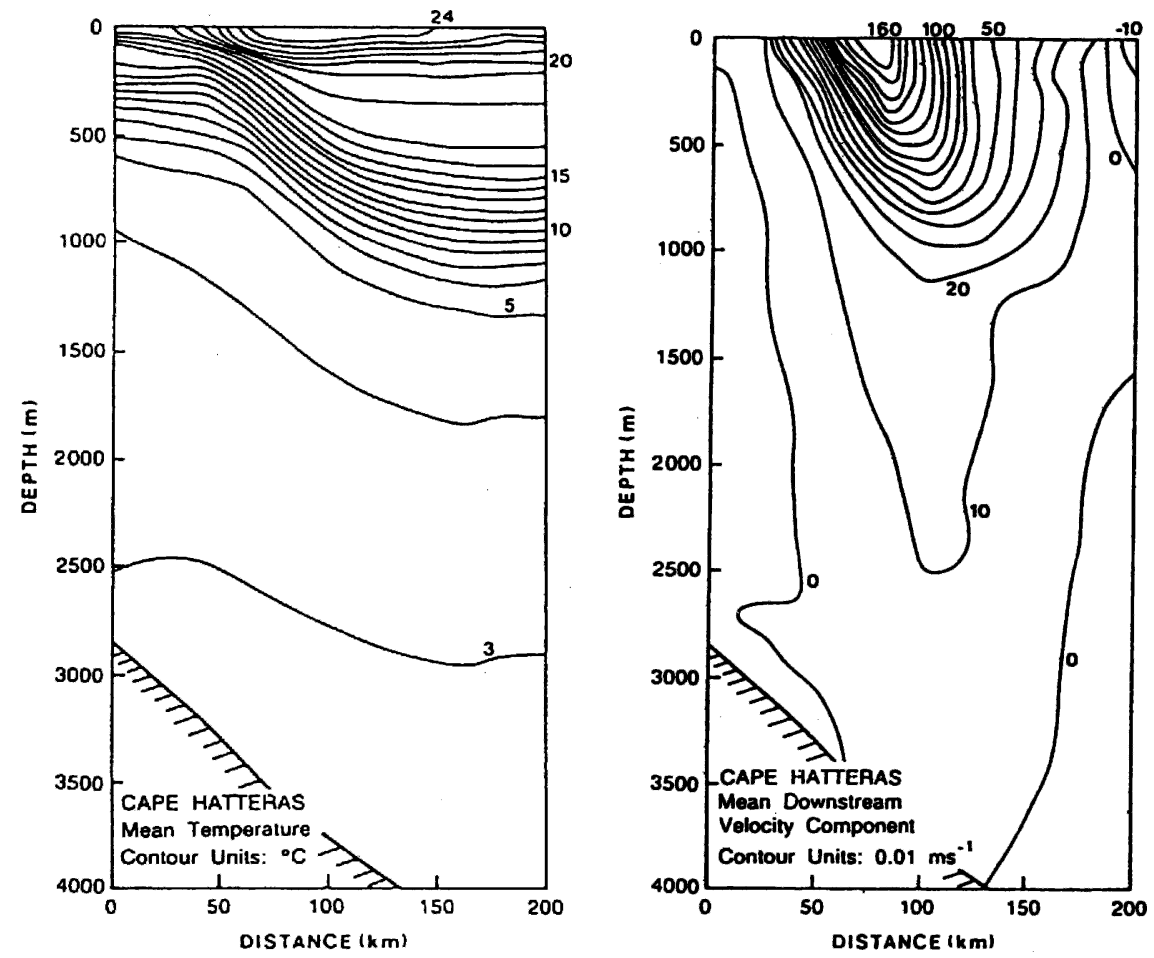

FIG. 5. (left) Temperature and (right) downstream velocity cross sections through the GS near $73^{\circ} \mathrm{W}$ in the Pegasus experiment, adopted from Leaman et al. (1989).

Gulf of Mexico is initialized according to the maximum temperature gradients in the main thermocline in the Levitus climatology shown in Fig. 8. Figure 9 shows the surface ocean currents after a 2-day integration in phase 1 during the forecast of Hurricane Isidore, initiated at 1200 UTC 19 September 2002. It is the same forecast as shown in Fig. 2, but it includes the initialization of the MCS in the Caribbean Sea and adjacent

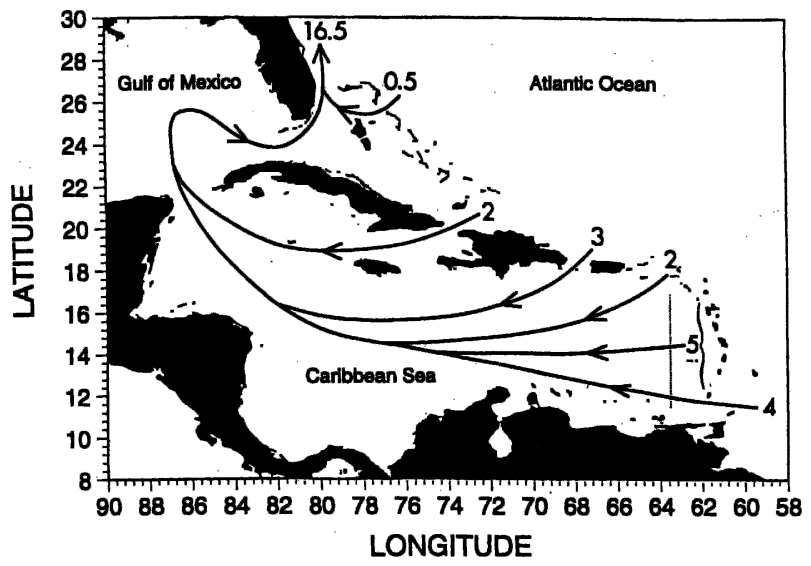

FIG. 6. Schematic representation of the circulation in the Caribbean Sea in the upper $200 \mathrm{~m}$, adopted from Johns et al. (1999). The numbers indicate transport in Sverdrups. regions and uses the hybrid GDEM/Levitus climatology. We see that a stable continuous multicurrent system is developed that resembles the schematic representation of the circulation in Fig. 6. The penetration of the LC into the Gulf of Mexico according to the Levitus climatology is significantly deeper than was obtained from GDEM data. The currents merge and provide a source for the LC. It is interesting to evaluate the vertical structure of the initialized currents in the model. Sheinbaum et al. (2002) processed direct ocean observations across the Yucatan Channel. Figure 10 (left), adopted from their paper, shows the mean alongchannel current obtained from moorings located along the line connecting the closest points of Yucatan and Cuba. Meridional velocity in the cross section along $21.5^{\circ} \mathrm{N}$ (Yucatan Channel) after 3 days of the coupled Hurricane Isidore forecast (initiated at 1200 UTC 19 September 2002) is shown in Fig. 10 (right). In spite of the positions of the cross sections in the left- and righthand panels of Fig. 10 being somewhat different, the structures and velocity magnitudes of the currents in the model and observations show great deal of similarity.

This example demonstrates that the new procedure can successfully initialize a complex multicurrent system in the ocean. We should note, however, that the 

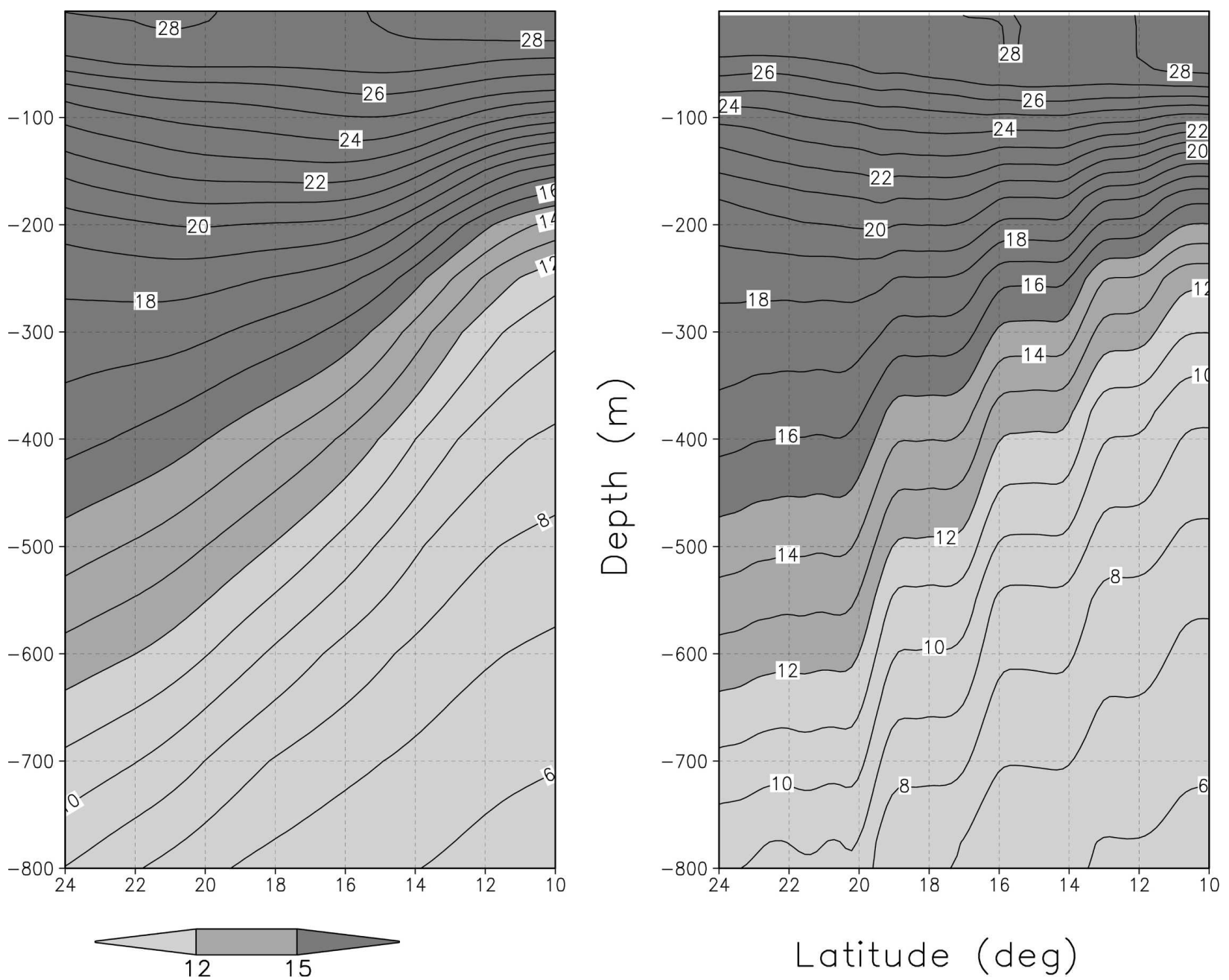

FIG. 7. Temperature cross sections along $54^{\circ} \mathrm{W}$ from $10^{\circ}$ to $24^{\circ} \mathrm{N}$ : (left) in the hybrid GDEM and Levitus field and (right) after phase 1 of the MCS model initialization during Hurricane Isidore forecast.

MCS that we initialize in this example represents an average and rather simplified view of the real circulation in the Caribbean Sea and surrounding regions. Presently available data do not allow a more accurate specification of synoptic variability in the position and intensity of each current in the MCS. As more observational data become available in the future, it will allow the detection of fronts in real time, and the new data can be assimilated using the present methodology without difficulty.

Figure 11 shows the currents in the Caribbean Sea and the LC area after 3 days of the Hurricane Isidore forecast, at the surface (left) and at $200 \mathrm{~m}$ (right), respectively. By that time, the ocean model had been integrated 8 days ( 2 days in phase 1, 3 days in phase 2, and 3 days in the coupled model). The hurricane track (open circles) is shown at 6-h intervals for 3 days of the forecast. In addition, the real track (hurricane symbols) is also shown at 6-h intervals for 3 days of the forecast and 3 days prior the beginning of the forecast. Slowly moving Isidore crossed the LC, and the hurricane wind stress produced a significant disturbance in the surface current. It is interesting that the hurricane primarily disturbed the upper layer of the ocean. The LC position and structure remained mostly intact at a depth of $200 \mathrm{~m}$.

Figure 12 shows the meridional velocity in a cross section along $25.5^{\circ} \mathrm{N}$ from $82^{\circ}$ to $89^{\circ} \mathrm{W}$ before (left) and after (right) Isidore crossed the LC. In this region, the LC makes a sharp loop as it penetrates into the Gulf of Mexico. Therefore, we see the northward (positive velocity) and southward (negative velocity) branches of the LC, located close to each other, with well-defined and strong currents in the upper ocean and main thermocline. It is evident that Isidore disturbed the currents only in the upper $70 \mathrm{~m}$ of the northward-moving branch. 


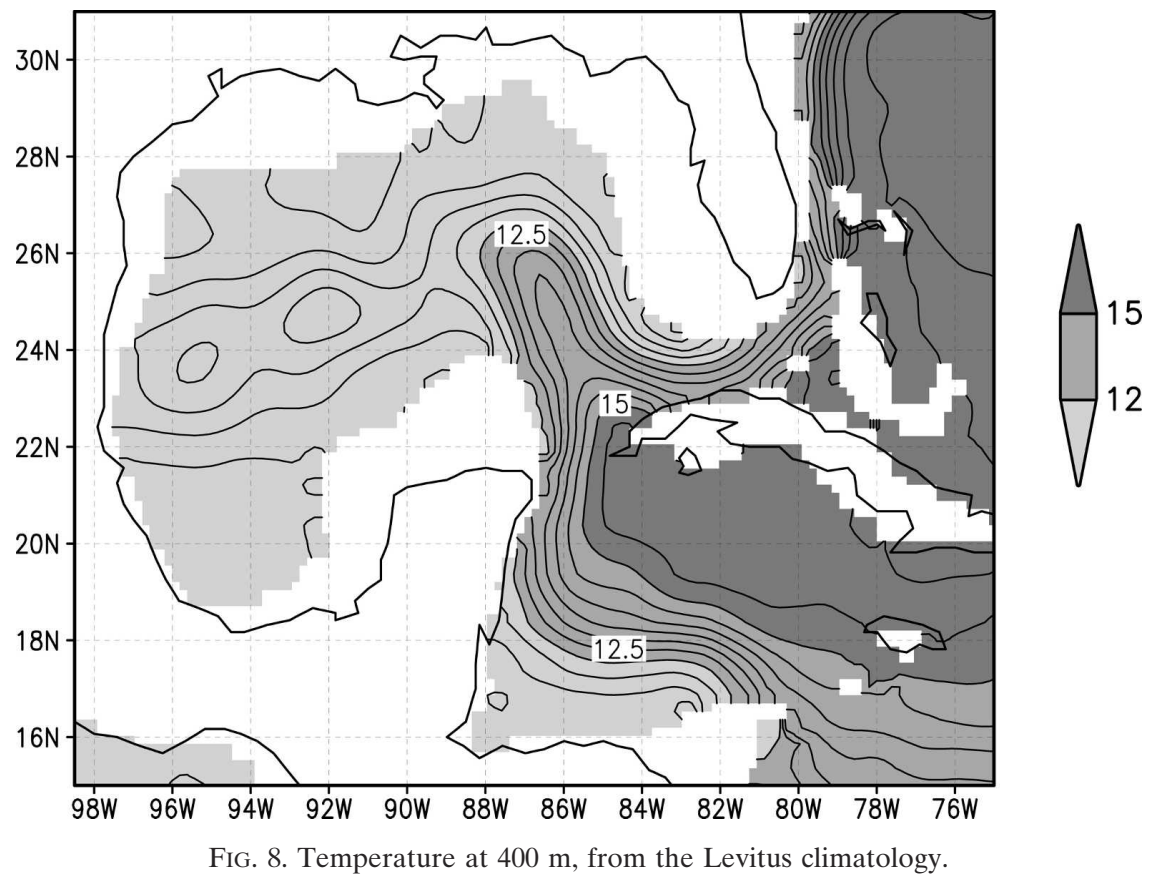

It is known that hurricane-induced SST cooling is The LC separates two very different water masses: the very sensitive to the depth of the mixed layer [e.g., see Gulf of Mexico has a much shallower mixed layer than a review article by Ginis (2002)]. The SST cooling is the Caribbean Sea. Thus it is reasonable to assume that usually increased if the mixed layer depth is shallower. the LC location may affect the SST cooling and hurri-

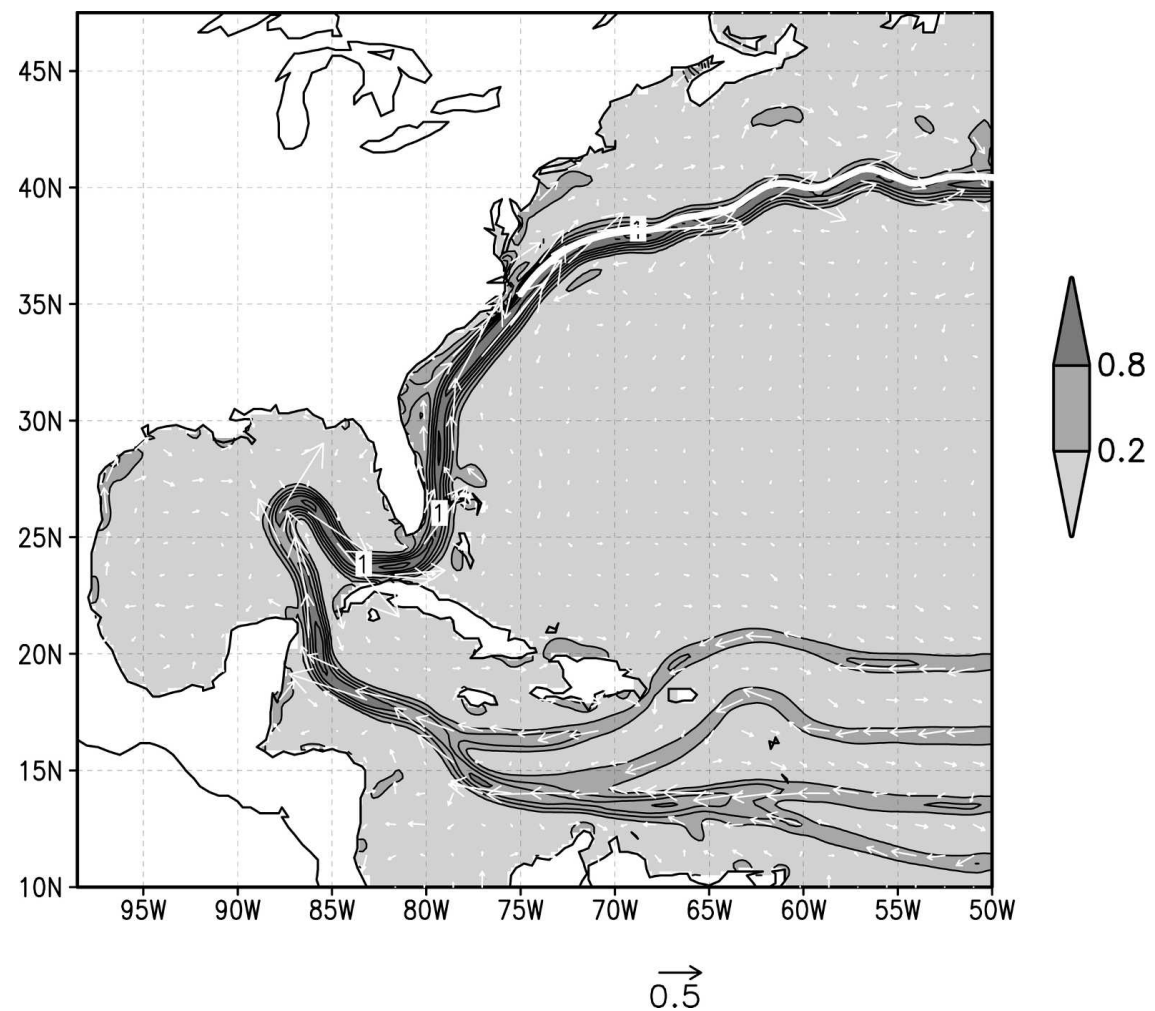

FIG. 9. The same as in Fig. 2 but after phase 1 of the MCS model initialization and using a hybrid of GDEM and Levitus data. 

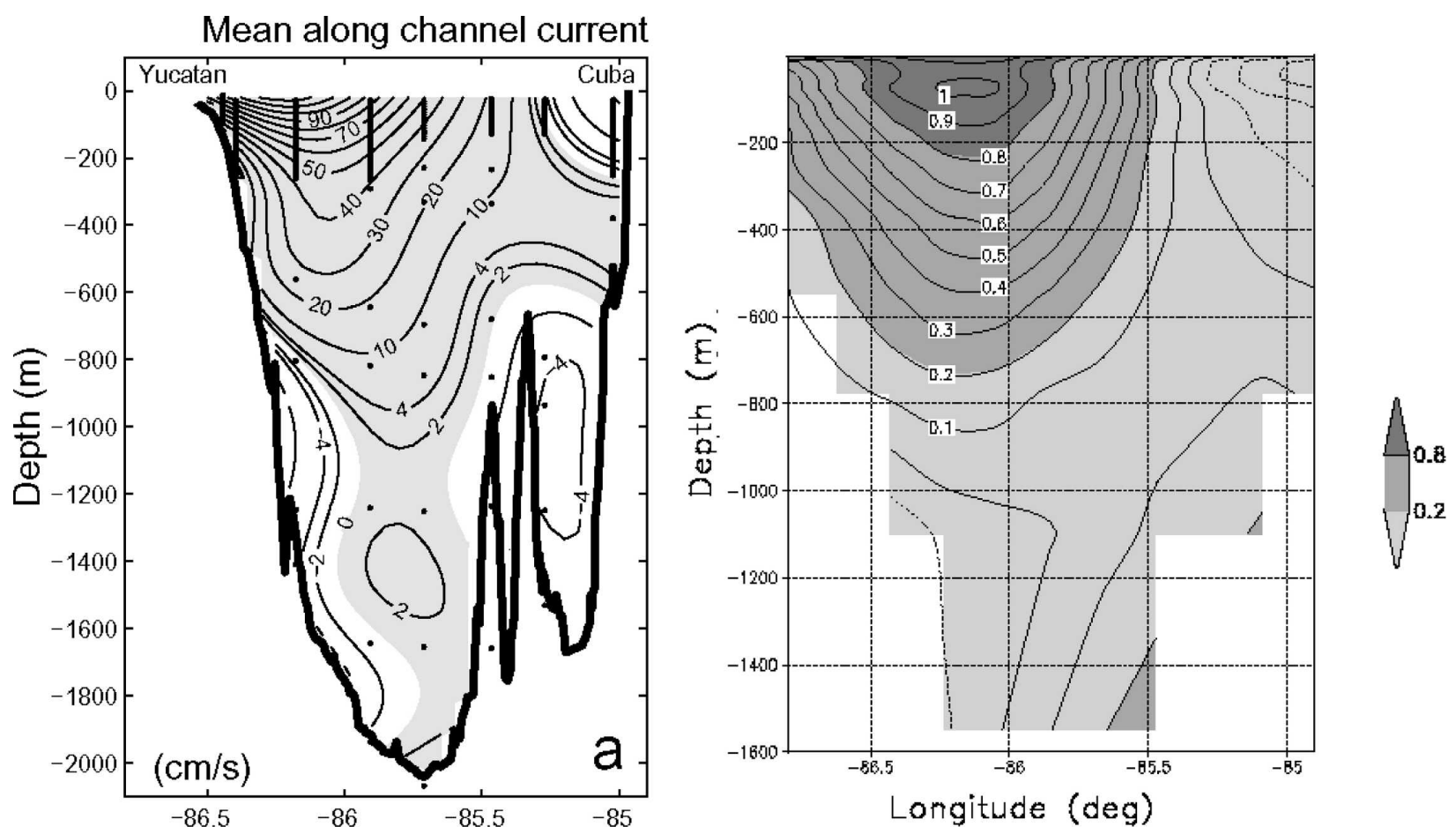

FIG. 10. Mean current along the Yucatan Channel, adopted from Sheinbaum et al. (2002). Shading indicates (left) flow into the Gulf of Mexico and (right) meridional velocity in the cross section along $21.5^{\circ} \mathrm{N}$ after 3 days of the coupled Hurricane Isidore forecast with the MCS initialization.

cane intensity when a hurricane slowly crosses the LC. Figure 13 shows the SST after 3 days of the Hurricane Isidore coupled forecast using OP03 (left) and MCS (right) ocean initializations. The hurricane tracks are

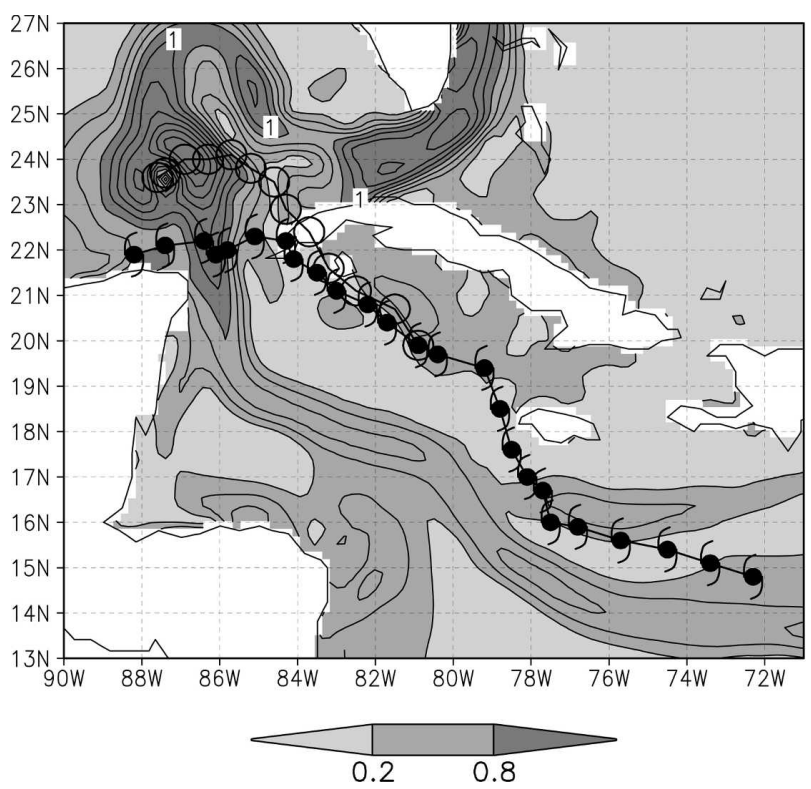

shown as in Fig. 11. The most important difference in the OP03 and MCS initializations is the difference in the LC penetration into the Gulf of Mexico. In the MCS initialization, we utilize the LC using the Levitus

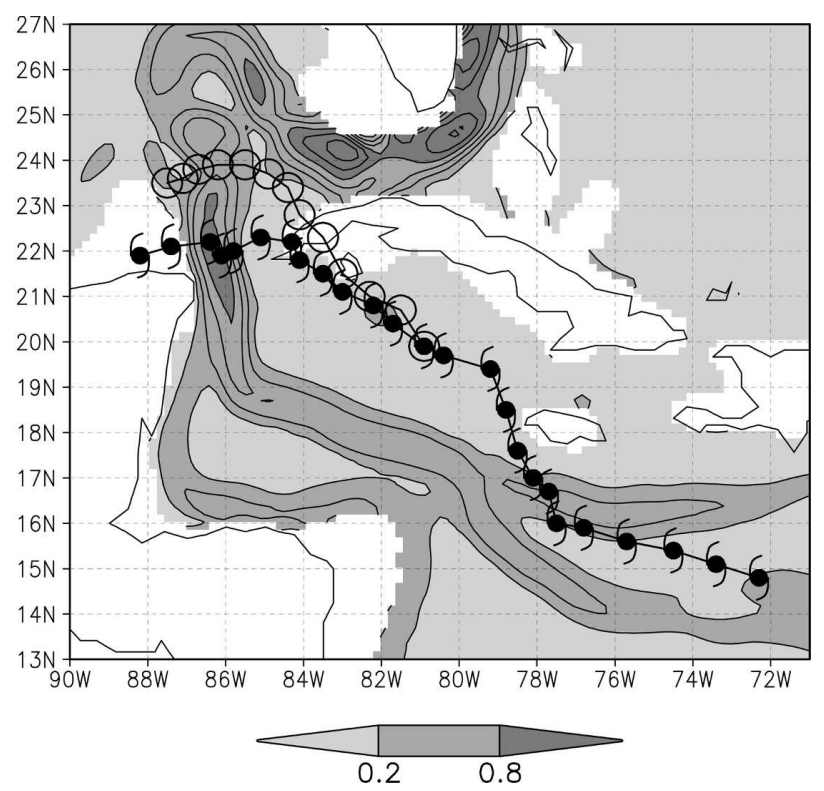

FIG. 11. Currents in the Caribbean Sea and the LC area after 3 days of the coupled Hurricane Isidore forecast at (left) the surface and (right) $200 \mathrm{~m}$ with the MCS initialization. The hurricane symbols and open circles indicate the observed and forecast tracks at 6-h intervals, correspondingly. 

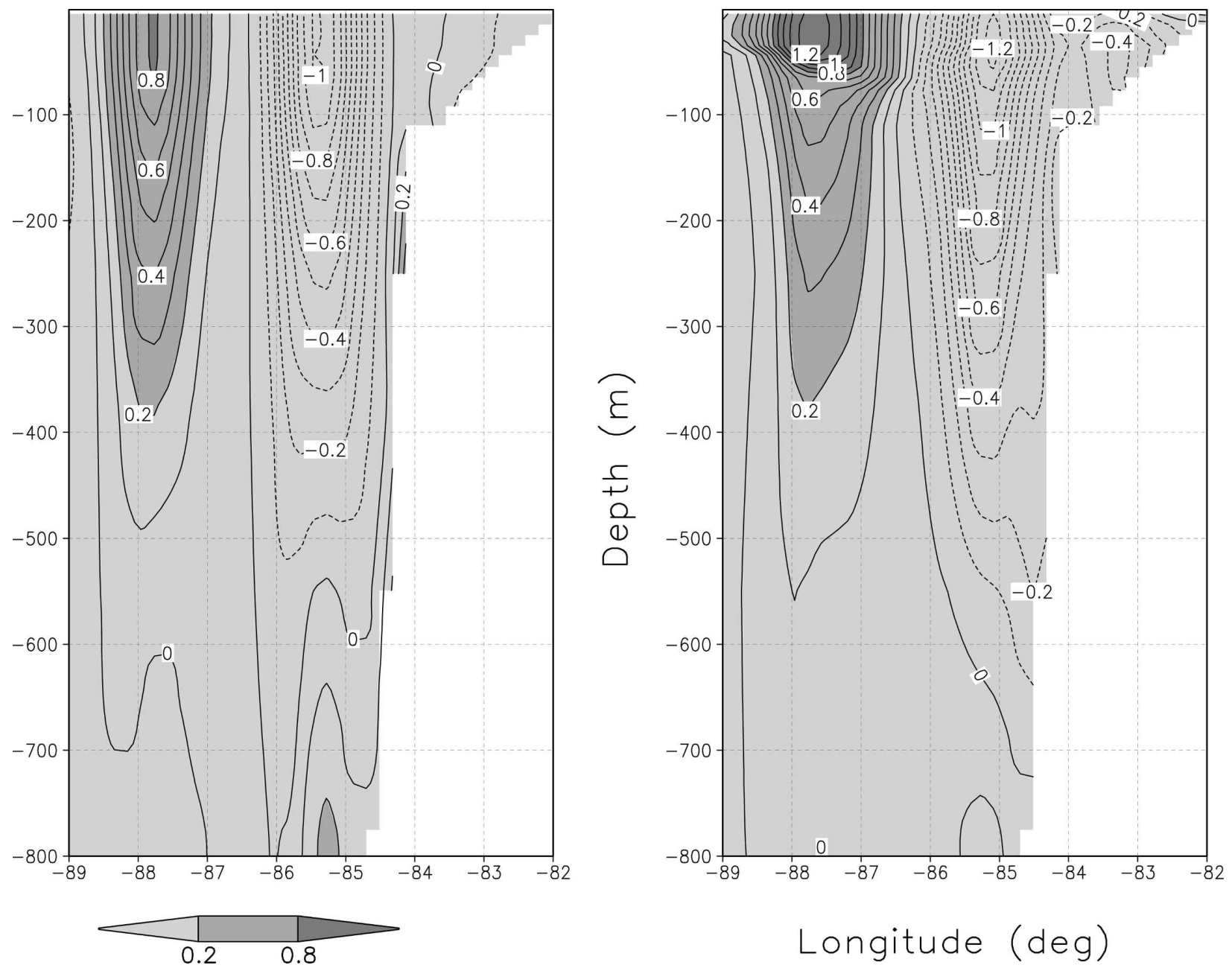

FIG. 12. Meridional velocity in a cross section along $25.5^{\circ} \mathrm{N}$ : (left) after phase 1 and (right) after 3 days of the coupled Hurricane Isidore forecast with the MCS initialization.

climatology for the month of September, which has a deeper penetration of the LC into the Gulf of Mexico compared to that in the OP03 initialization based on the GDEM climatology. According to the satelliteretrieved sea surface height (SSH) data, the LC path derived from the Levitus data is in a better agreement with the real LC path during the time when Hurricane Isidore crossed the LC. In OP03, the hurricane produced a strong SST decrease as it moved into the Gulf of Mexico with a shallow mixed layer. In MCS, the LC penetrates significantly deeper in the Gulf of Mexico and advects the Caribbean Sea water masses with a deep mixed layer in the Gulf of Mexico. As a result, the SST decrease in this case is significantly less than in OP03.

We calculated two sets of five successive 3-day Hurricane Isidore forecasts, with a 12 -h interval beginning at 1200 UTC 18 September and ending at 1200 UTC 20
September 2002. The only difference between the two sets was a different ocean initialization: $\mathrm{OP} 03$ in the first set and MCS in the second set. The forecast rms errors for minimum pressure (Fig. 14) clearly demonstrate sensitivity of the hurricane intensity forecast to the different ocean initializations. Note that the forecasts display rather significant track errors for these cases. These errors are mainly dependent on the atmospheric model's ability to simulate hurricane internal dynamics and its interaction with the surrounding environment and are not sensitive to the ocean initialization procedure.

We have developed an algorithm that can initialize the LC in the GFDL/URI hurricane model with virtually any given path. Satellite-retrieved SSH data and the results from the Global Ocean Data Assimilation Experiment (GODAE) can be utilized in the future for this purpose. For example, the SSH data will be used to 

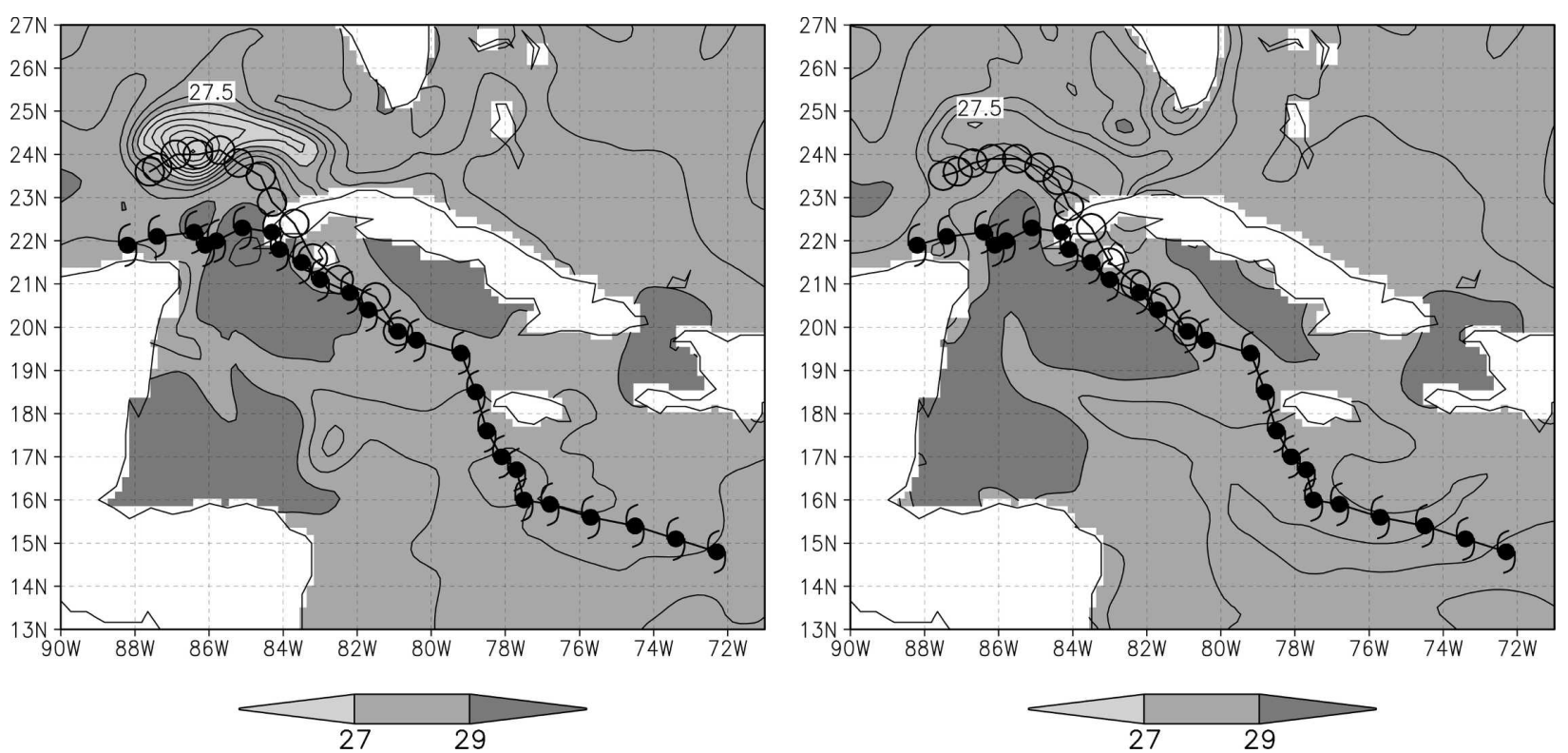

FIG. 13. Sea surface temperature after 3 days of the coupled Hurricane Isidore forecast using (left) OP03 and (right) MCS initializations. The hurricane symbols and open circles indicate the observed and forecast tracks at 6-h intervals, correspondingly.

determine how far the northern boundary of the LC penetrates into the Gulf of Mexico at the beginning of a hurricane forecast. Based on this information, the LC path is constructed and applied to the ocean initial con-

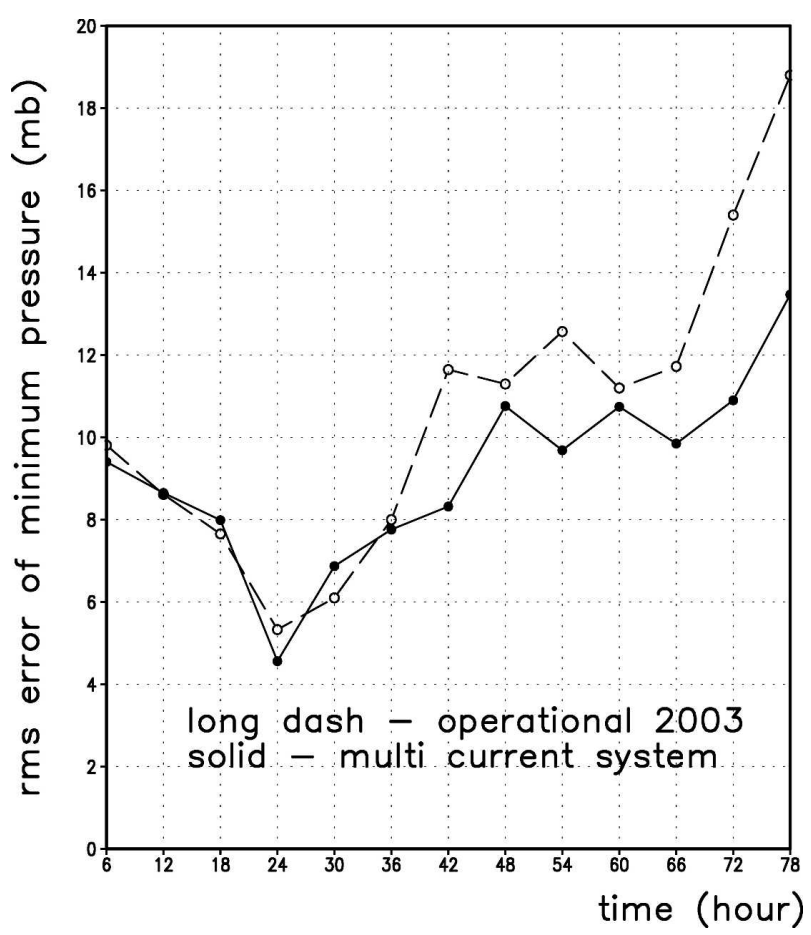

FIG. 14. Rms errors of minimum pressure for five successive 3-day coupled Hurricane Isidore forecasts with the OP03 (dashed) and MCS (solid) initializations. ditions using our initialization procedure. We have tested this algorithm for various northern boundaries of LC penetration into the Gulf of Mexico using historic satellite data. Figure 15 shows the surface currents after a 5-day integration of the ocean model initialized using the maximum known penetration of the LC into the Gulf of Mexico. We specially selected this extreme case to evaluate whether the initialization procedure and ocean model are able to simulate a very steep curvature, in which the northward and southward branches of LC are very long and located very close to each other. As seen in Fig. 15, the model is able to handle this extreme case very well, producing a continuous, strong, and stable current.

\section{Summary}

A new ocean assimilation and initialization procedure has been developed for use in coupled oceanatmosphere hurricane forecasts. It was designed to obtain more realistic initial conditions, including the position and structure of the Gulf Stream and Loop Current, in the GFDL/URI coupled hurricane prediction system used operationally at the National Centers for Environmental Prediction. This new procedure is based on a feature modeling approach that allows a realistic simulation of the cross-frontal temperature, salinity, and velocity of oceanic fronts. While the feature models developed in previous studies are based on analytical formulas, the major innovation in the new pro- 


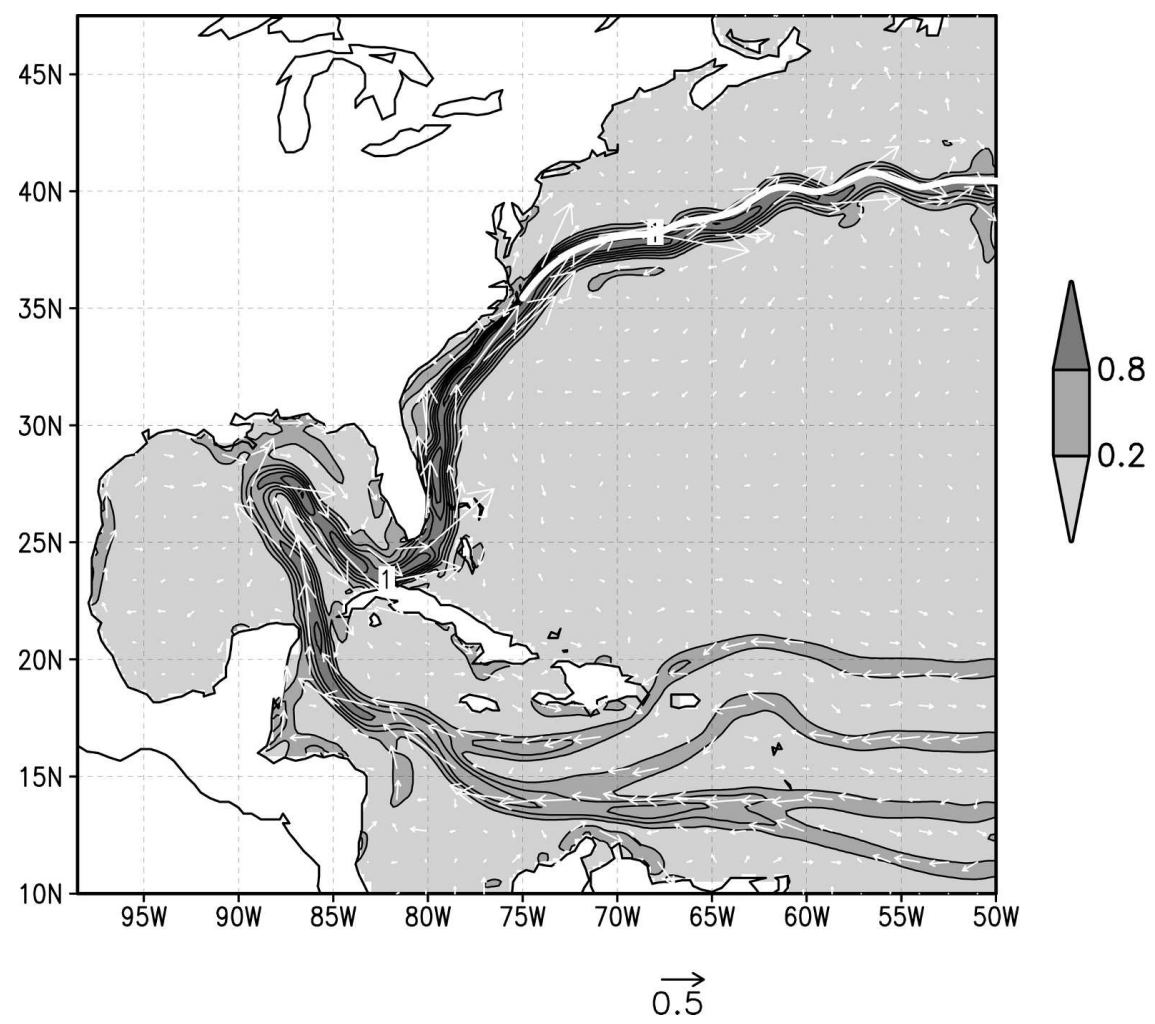

FIG. 15. Surface currents after a 5-day integration of the ocean model initialized using maximum LC penetration into the Gulf of Mexico with the MCS initialization.

cedure is cross-frontal "sharpening" of the background temperature and salinity fields across the fronts. The sharpening is guided by observed cross sections of the GS obtained in specialized field programs.

We also developed a feature-modeling approach for the initialization of multicurrent systems in the Caribbean Sea and adjacent regions that provide the source of the LC. After a 2-day model integration, a stable continuous multicurrent system developed that resembled the schematic representation of the circulation in the Caribbean Sea. The model velocity cross section through the Yucatan Channel compared quite well with observations.

The examples of the new initialization procedure discussed in the paper were largely based on the ocean climatology. The only synoptic part of the initialization is the use of NCEP SST. However, it was demonstrated that the new procedure allows the initialization of the observed range of the LC paths in the Gulf of Mexico. Satellite-retrieved technology is presently being developed that will detect the LC path in real time based on sea surface height data, together with new data assimilation procedures under the auspices of the Global Ocean Data Assimilation Experiment (GODAE). It will help to determine how far the northern boundary of the LC penetrates into the Gulf of Mexico at the time of a hurricane forecast. The real-time LC path information can be utilized in the initialization procedure presented in this paper without significant difficulties.

Acknowledgments. This work was partially funded by the Joint Hurricane Testbed (JHT) administered by the United States Weather Research Program (USWRP).

\section{REFERENCES}

Bao, J.-W., J. M. Wilczak, J.-K. Choi, and L. H. Kantha, 2000: Numerical simulations of air-sea interaction under high wind conditions using a coupled model: A study of hurricane development. Mon. Wea. Rev., 128, 2190-2210.

Bender, M. A., and I. Ginis, 2000: Real-case simulation of hurricane-ocean interaction using a high-resolution coupled model: Effects on hurricane intensity. Mon. Wea. Rev., 128, 917-946.

Blumberg, A. F., and G. L. Mellor, 1987: A description of a threedimensional coastal ocean circulation model. ThreeDimensional Coastal Ocean Models, N. Heaps, Ed., Amer. Geophys. Union, 208 pp.

Bower, A. S., and N. G. Hogg, 1996: Structure of the Gulf Stream and its recirculations at $55^{\circ}$. J. Phys. Oceanogr., 26, $1002-$ 1022.

Boyer, T. P., and S. Levitus, 1997: Objective Analysis of Tempera- 
ture and Salinity for the World Ocean on a 1/4 Grid. NOAA Atlas NESDIS 11, 62 pp.

Cornillon, P., and D. R. Watts, 1987: Satellite thermal infrared and inverted echo sounder determinations of the Gulf Stream northern edge. J. Atmos. Oceanic Technol., 4, 712-723.

Emanuel, K. A., 1999: Thermodynamic control of hurricane intensity. Nature, 401, 665-669.

Gangopadhyay, A., and A. R. Robinson, 1997: Circulation and dynamics of the western North Atlantic. Part III: Forecasting the meanders and rings. J. Atmos. Oceanic Technol., 14, $1352-1365$

$\longrightarrow$, and - 2002: Feature oriented regional modeling of oceanic fronts. Dyn. Atmos. Oceans, 36, 201-232.

,-- , and H. G. Arango, 1997: Circulation and dynamics of the western North Atlantic. Part I: Multiscale feature models. J. Atmos. Oceanic Technol., 14, 1314-1332.

Ginis, I., 2002: Tropical cyclone-ocean interactions. AtmosphereOcean Interactions, W. Perrie, Ed., Advances in Fluid Mechanics Series, Vol. 33, WIT Press, 83-114.

Halkin, D., and T. Rossby, 1985: The structure and transport of the Gulf Stream at $73^{\circ}$ W. J. Phys. Oceanogr., 15, 1439-1452.

Hogg, N. G., 1992: On the transport of the Gulf Stream between Cape Hatteras and the Grand Banks. Deep-Sea Res., 39, 1231-1246.

Johns, E., W. D. Wilson, and R. L. Molinari, 1999: Direct observations of velocity and transport in the passages between the Intra-Americas Sea and the Atlantic Ocean, 1984-1996. J. Geophys. Res., 104, 25 805-25 820.

Johns, W. E., T. J. Shay, J. M. Bane, and D. R. Watts, 1995: Gulf Stream structure, transport, and recirculation near $68 \mathrm{~W} . J$. Geophys. Res., 100, 817-838.

Lai, A., W. Qian, and S. M. Glenn, 1994: Data assimilation and model evaluation experiment datasets. Bull. Amer. Meteor. Soc., 75, 793-809.
Leaman, K. D., E. Johns, and T. Rossby, 1989: The average distribution of volume transport and potential vorticity with temperature at three sections across the Gulf Stream. J. Phys. Oceanogr., 19, 36-51.

Lozano, C. J., A. R. Robinson, H. G. Arango, A. Gangopadhyay, N. O. Sloan, P. J. Haley, and W. G. Leslie, 1996: An interdisciplinary ocean prediction system: Assimilation strategies and structured data models. Modern Approaches to Data Assimilation in Ocean Modelling, P. Malanotte-Rizzoli, Ed., Elsevier Oceanography Series, Elsevier Science, 413-452.

Robinson, A. R., and A. Gangopadhyay, 1997: Circulation and dynamics of the western North Atlantic. Part II: Dynamics of meanders and rings. J. Atmos. Oceanic Technol., 14, 1333 1351.

_, S. M. Glen, M. A. Spall, L. J. Walstad, G. M. Gardner, and W. G. Leslie, 1989: Forecasting GS meander and rings. Eos, Trans. Amer. Geophys. Union, 70, 1464-1473.

Rossby, T., and E. Gottlieb, 1998: The Oleander Project: Monitoring the variability of the Gulf Stream and adjacent waters between New Jersey and Bermuda. Bull. Amer. Meteor. Soc., 79, 5-18.

- and H. M. Zhang, 2001: The near-surface velocity and potential vorticity structure of the Gulf Stream. J. Mar. Res., 59, 949-975.

Sheinbaum, J., J. Candela, A. Badan, and J. Ochoa, 2002: Flow structure and transport in the Yucatan Channel. Geophys. Res. Lett., 29, 1040, doi:10.1029/2001GL013990.

Spall, M. A., and A. R. Robinson, 1990: Regional primitive equation studies of the Gulf Stream meander and ring formation region. J. Phys. Oceanogr., 20, 985-1016.

Teague, W. J., M. J. Carron, and P. J. Hogan, 1990: A comparison between the generalized digital environmental model and Levitus climatology. J. Geophys. Res., 95, 7167-7183. 